\title{
Image Processing: Capturing Student Attendance Data
}

\author{
Hendra Kurniawan(1), Melda Agarina(2), Suhendro Yusuf Irianto(3) \\ ${ }^{(1,2,3)}$ Lecturer, Department of Computer Scince, IIB Darmajaya, Indonesia
}

\section{Abstract}

Role of the student attendance record is very important in the primary, secondary, and tertiary education. The purpose of this record is monitoring student activity in the teaching and learning process and regarded as one of the important learning assessments. Moreover, a data processing for recording the student attendance is currently done in various ways such as fingerprint, radio frequent identification (RFID), facial recognition system, android-based application, and others. However, many conventional ways (i.e., using paper-based system) are still used, especially in Indonesia. This is because several universities still rarely have enough funds for developing innovative systems. In this research, the image processing application for capturing student attendance data was built. The objective of this research was to provide an efficient alternative to monitor student activities in teaching and learning process. The image processing produced the information related to student attendance by scanning the attendance file through jpg/jpeg using learning vector quantization (LVG) as the process model.

\section{Keywords}

Attendance List, Image Processing, Attendance List Image using LVQ

\section{INTRODUCTION}

Recording the student attendance is very important to carry out because it is an important effort to monitor the level of student activities in the classroom. Moreover, the students' attendance can also be used as a lecturers' assessment. The student attendance record is done in the primary, secondary, and tertiary education. There are various ways to record the student attendance e.g., recording through the paper, fingerprint, and web camera using image processing. These are the methods to record the student attendance. The image processing has largely been done by researchers from lecturer-researcher, studentresearcher, and publics to solve problems and find the solution in the real life [1][2][3]. One of the researches related to the image processing which is in line with this article is the research conducted by Siswo Wardoyo, Romi Wiryadinata, and Raya Sagita. Their title was "the eigenface-based facial recognition system through principal component analysis method". In this research, the webcam was used as a tool to capture the facial image processed by the principal component analysis method. The image processing was processing the pixels images in the form of digital images for a particular purpose [2]. Image processing was done for several reasons e.g., to obtain an original image of the degraded image due to noise or to obtain distinct and compatible images required for further phases in the image analysis [2]. The processed image was digitally transformed into a numerical representation by the computer as the processing result [2]. The method of this research used a learning vector quantization (LVQ). Learning Vector Quantization (LVQ) was the learning-based method carried out on a supervised competitive layer. A competitive layer automatically learnt to classify input vectors. The obtained classes were as a result of this competitive layer and depended only on the range among the input vectors. If two vectors were approximately equal, the competitive layer placed the input vectors into the same class [1]. LVQ was the pattern classification method on each output representing a particular category or class (some units of the output should be used for each class). The weight vector for an output was often expressed as a reference vector. It was assumed that a series of training patterns with the provided classifications was along with an initial distribution of the reference vector. After the training was finalized, the LVQ network clarified the input vectors by assigning it to the same class as the output unit; while, the reference vectors were classified as the input vectors [3]. LVQ architecture was seen as picture 2 below:

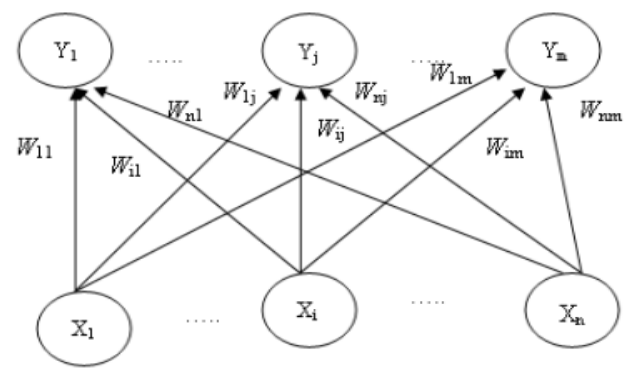

Figure 1: Architecture of LVQ [3] 
The LVQ algorithm was as follows:

1. Specify:

Weight (w), maximum epochs, expected minimum errors (eps), learning rate (a).

2. Put:

Input: $x(m, n)$

Target: $T(1, n)$

3. Set an initial condition:

epoch = 0;

err $=1$;

4. Do if: (epoch < maximum epoch) or $(\alpha>$ eps $)$

a. epoch $=$ epoch +1 ;

b. Do it for $i=1$ to $n$

i. Set $\mathrm{j}$ in this wise to minimization of $\| \mathrm{x}$ - wj $\|$ minimum (Cj)

ii. Fix wj with the condition:

if $T=C j$, then wj $(n e w)=w j($ old $)+\alpha(x-w j($ old $))$

if $T$ is not equal to $C j$, then wj (new) $=$ wj (old) $-\alpha(x-w j($ old $))$

c. Subtract the value of $\alpha$

\section{ACADEMIC DISCIPLINE And SUB-DISCIPLINES}

Programming, Database

\section{SUBJECT CLASSIFICATION}

Computer Science

\section{GENERAL DESCRIPTION OF THE SYSTEM}

This research was conducted with several steps, as follows:

1. The student attendance files from which the images were take were the file consisting of a level of the clarity on color and text.

2. Scanner was used as the device used to capture the student attendance images

3. Segments of the identified student attendance images were the students' number, students' name, students' signature, sign ' $X$ ' , sign '-' or blank

4. The captured images were in the form of JPEG image file.

General framework to produce information related to the student attendance was seen in figure 2. The picture above means that the captured image was the processed images as the student attendance files in the form of paper. The tool used as the image catcher was a scanner. The image captured by the scanner was recorded and stored through JPEG file extension.

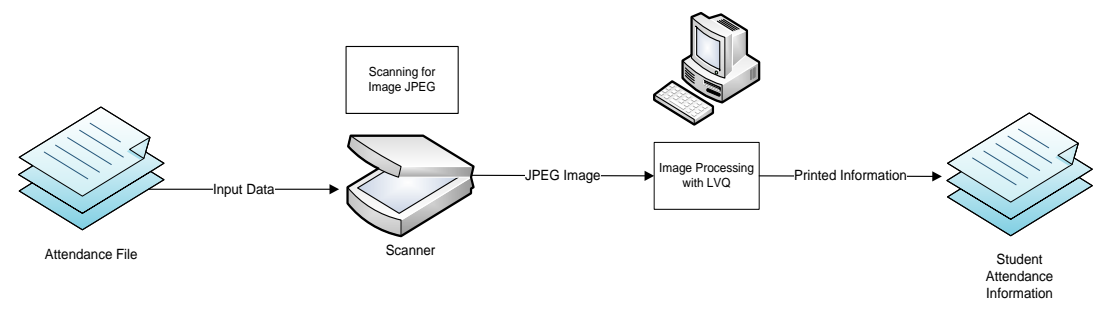

Figure 2. General Description of the System

According to the file, the application was able to recognize the existing pattern based on the created and set pattern from the physical attendance pattern itself. The program only recognized formatted characters in the application. The student attendance physical attendance picture was seen below. 


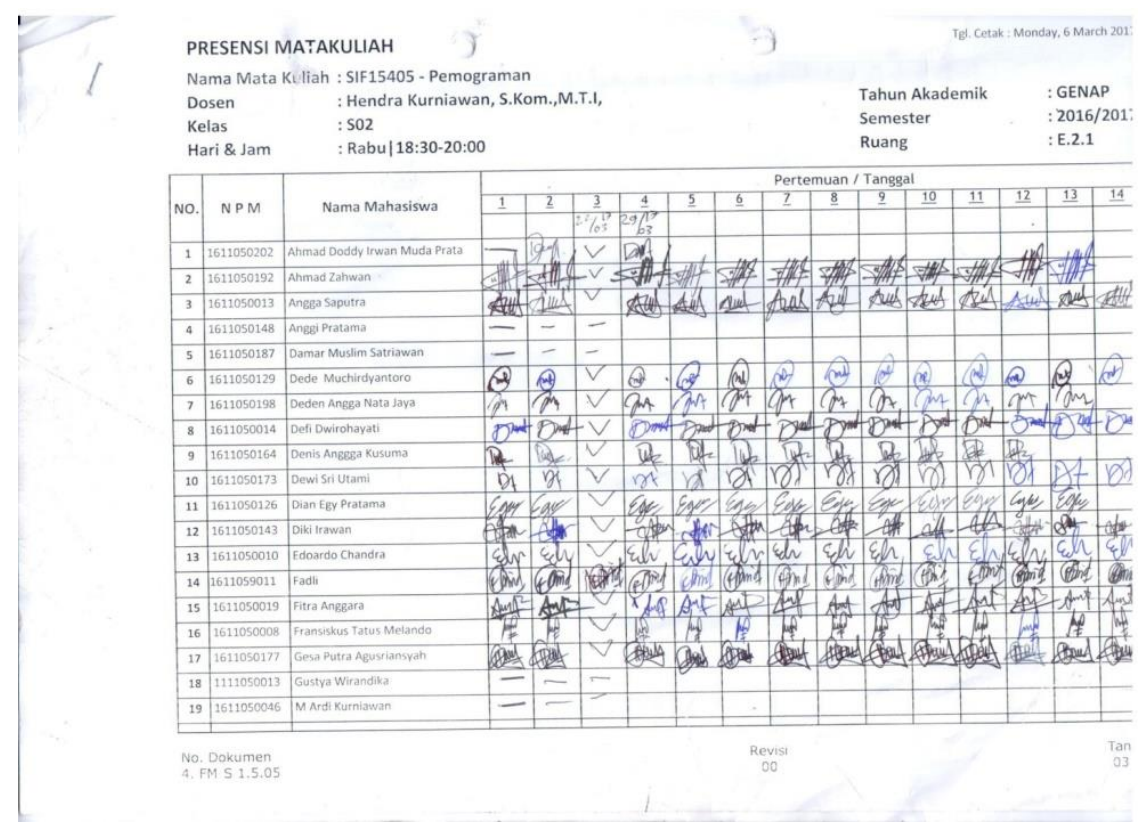

Figure 3. Student Presentation File

Based on the example of the attendance images which had been taken, the image processing application for capturing the student attendance was built with the introduction to the character numbers, letters, student signatures, and blank parts of the atteandance. The characters which had been identified were 0-9, A-Z, a-Z, , $\mathrm{X}$, and student signatures.

\section{PHASES OF DATA TRAINING PROCESS AND IMAGE DETECTION}

The training data process design was the design used to recognize tested letters with similar types of the letters. This process generated a new weight of the trained letters. Moreover, the image detection process was the process to find the student attendance file area based on the name and the existing signature. The description of the data training process and image detection was seen below.

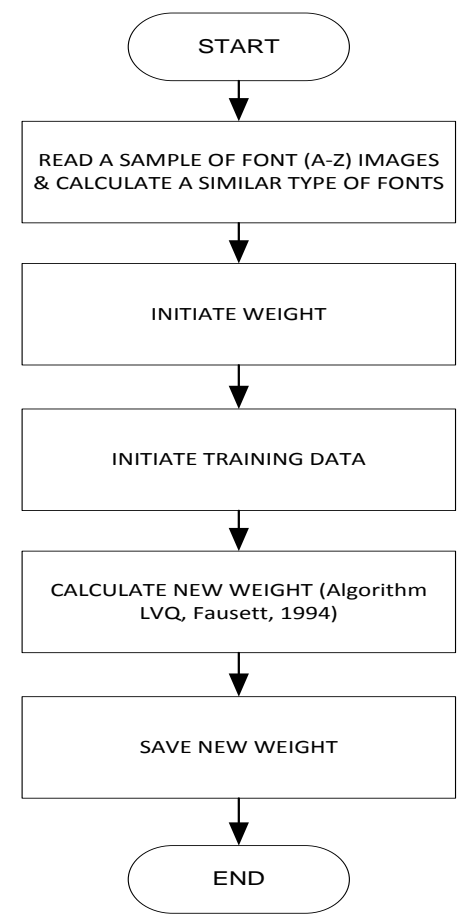

Figure 4. Data Training Processes 


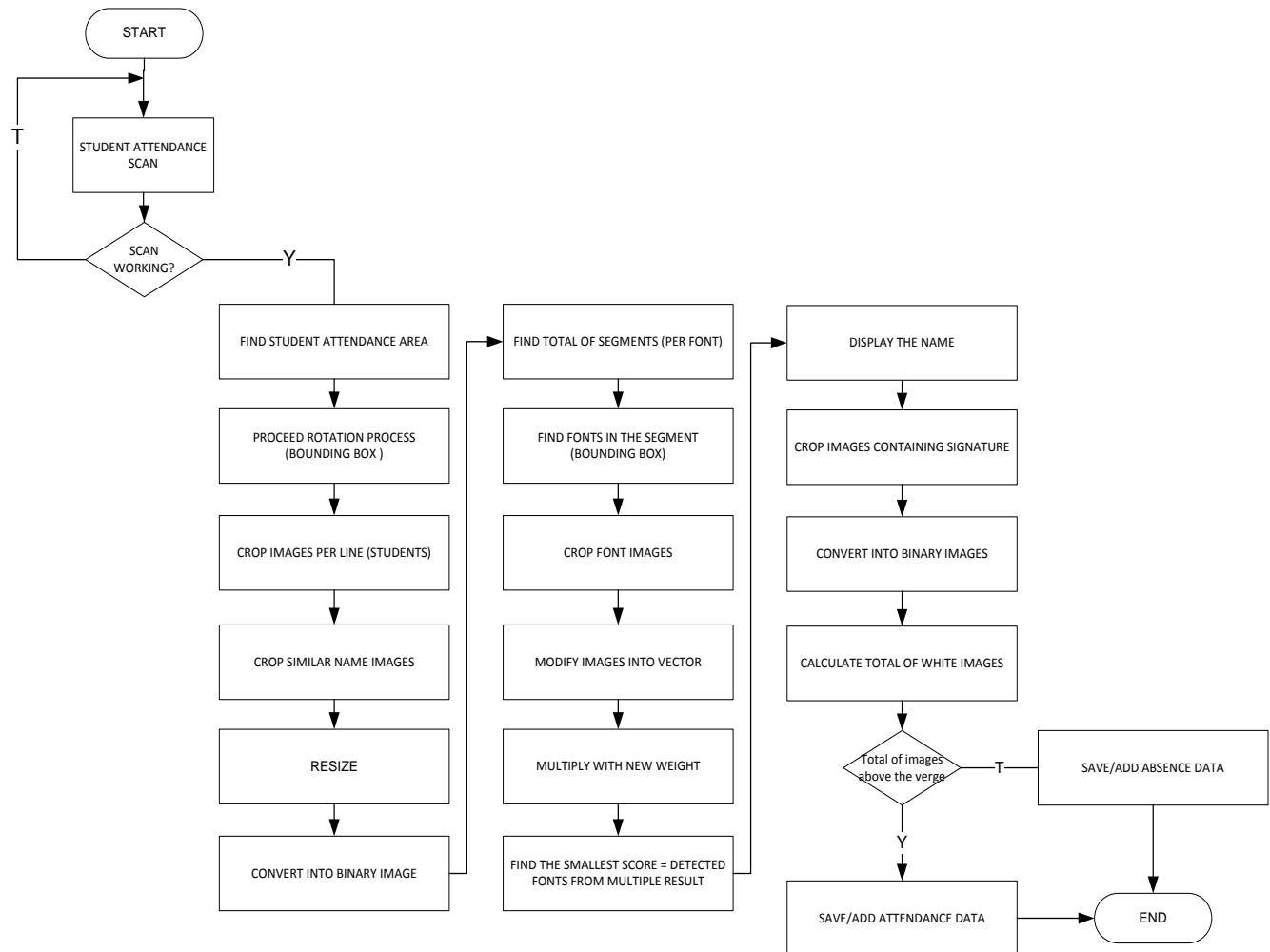

Figure 5. Image Detection Process

\section{RESULT OF THE IMAGE PROCESSING PROCESS}

The steps for processing the image were as follows:

\section{Data Process Training}

Steps:

1. Prepare a sample of letters using font from the attendance list divided into capital letters and small letters from which 4 fonts were provided. In this research, calibri, cambria, carlito, and candara font were used.

ABCDEFGHIJKLMNOPQR S T U V W X Y Z

ABCDEFGHIJKLMNOPQRSTU V W X YZ

ABCDEFGHIJKLMNOPQRSTUVWXYZ

ABCDEFGHIJKLMNOPQR S T U V W XY Z

Figure 4. Figure of Capital Letters

$$
\begin{gathered}
\text { abcdefghijklmnopqrstuv w x y z } \\
\text { abcdefghijklmnopqrstuv w x y z } \\
\text { abcdefghijklmnopqrstuvwxyz } \\
\text { abcdefghijklmnopqrstuv w x y z }
\end{gathered}
$$

Figure 5. Figure of Small Letter Font

2. Steps of the capital / small letters training:

a. Read the image containing a collection of letters. 


\section{abcdefghijklmnopqrstuvwxyz}

Figure 6. Original Image

b. Change the color to Grayscale.

c. Resize the font into 1.5 times of the original size.

\section{abcdefghijklmnopqrstuvwxyz}

d. Modify into binary image. In this step, the result of an image was black.

\section{abcdefghijklmnopqrstuvwxyz}

e. Invert the binary image. Convert the text and background into a reverted form. The text was white and the background was black.

\section{abcdefghijk/mnopqrstuvwxyz}

f. Find the bounding box per letter with the find contour function.

\section{abcdefghifk/mnopgrstuvw:yz}

g. Extract per letter with the mask obtained on the find contour function.

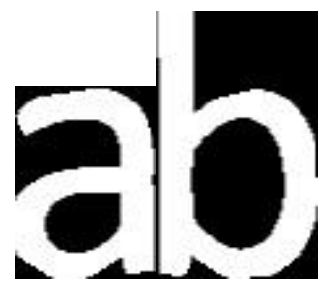

h. Put the letter in the middle of the image with the $45 \times 45$ in size.

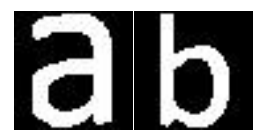

i. Calculate the white area on the letter before it was resized; if there were more than 200, put the image into the dataset.

j. In the first set of letters, the weight dataset was used and the second and further set of letters were used as the training dataset.

k. Do LVQ process

Testing Process

Steps:

1. Step of the capital/small letters:

a. Read the image containing a collection of letters.

b. Modify the color to grayscale.

C. Resize the font into 1.5 times of the original size.

Modify the binary image. In this step, the result of an image was black.

d. Invert the binary image. Convert the text and background into reverted from. The text was white and the background was black.

e. Find the bounding box per letter with the find contour function.

f. Extract the letters with masks obtained in the find contour function. 
g. Put the letters in the middle of the image with the $45 \times 45$ in size.

h. Calculate the white area on the letter. If there were more than 200, put the image input as a examined image

i. Do the detection process with LVQ.

j. Calculate the accuracy.

\section{Letter Detection Process}

\section{Steps:}

a. Find the area containing students' data and signatures

Method

- Find the largest rectangle area by using find contour

- Rotate to get the appropriate image

b. Calculate the total data of the image with the known row height in the high sample by 54 pixels per line

c. Crop the images containing students' data and signature Ahmad Insanuridho

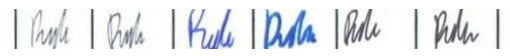

d. Crop images containing students' name Ahmad Insanuridho

e. Resize the font into 20 fold

\section{Ahmad Insanuridho}

f. Modify the image containing the students' name to the binary

g. Do the inverted binary

\section{Ahmad Insanuridho}

h. Split the image per word segment through a space (if the columns without white $>155$, create a new segment)

\section{Ahmad}

\section{Insanuridho}

i. Modify the image per word segment to the binary image

j. Invert the binary image per word segment.

k. Find the bounding box per letter with the find contour function 


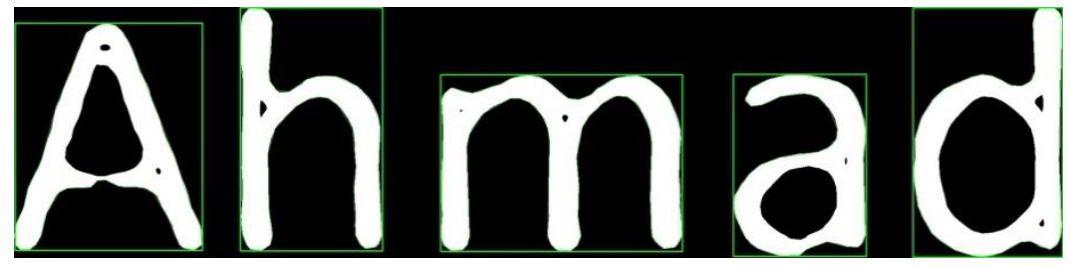

I. Extract per letter with the mask obtained in the find contour function

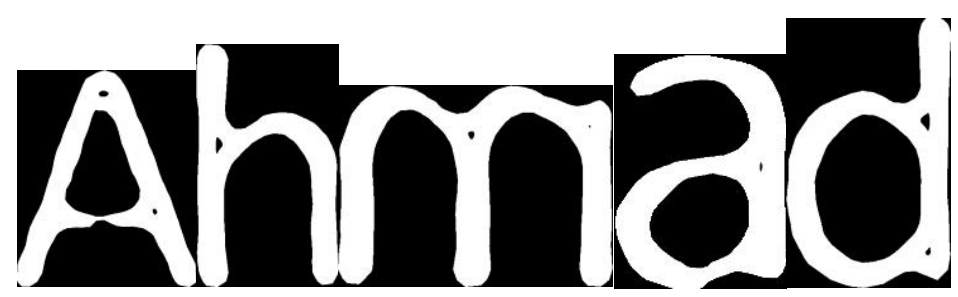

m. Resize the image and put the letters in the middle of the image with $45 \times 45$ in size

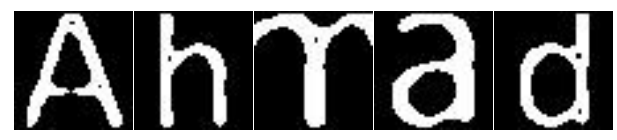

n. Calculate the white area on the letter image that has not been resized. If more than 7000 , then put the resized image as the detected image

o. Check whether its status is an initial image segment or not. If the status was the initial image, use use the capital letter detection; otherwise, use the small letter detection

p. Do the detection until end of the segment

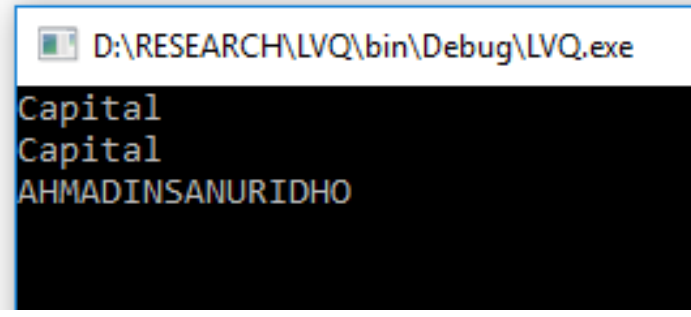

An image processing application for capturing the student attendance was as follow:

\begin{tabular}{|l}
\hline Form1 \\
\hline \\
\hline \\
\hline
\end{tabular}




\section{CONCLUSION}

This application is the graphical user interface application that functions to process the paper-based student attendance images. Moreover, this application is captured through the scanning process by using a filecharacterized scanner with JPEG extension. The type of this method is the learning vector quantization (LVQ). Some of the steps to obtain the student attendance data include italic letters, letter test, letter detection, and attendance detection training.

\section{ACKNOWLEDMENT}

We would like to express a special gratitude to the Ministry of Research and Technology of Higher Education in Jakarta for financing this research. Furthermore, we also thank to the institution of the research and learning development and community service of Informatics and Business Darmajaya, Bandar Lampung. We also thank the colleagues who have provided support so that this scientific article can be completed.

\section{REFERENCES}

[1] Budianita. Elvia. 2013. "Penerapan Learning Vector Quantization (LVQ) untuk Klasifikasi Status Gizi Anak", Tesis, Jurusan Ilmu Komputer Universitas Gajah Mada.

[2] URL : http://www.ittelkom.ac.id/library/index.php?option=com content\&view=article\&id=383:citradigital

[3] Fausset, L.V. 1994. Fundamentals of Neural Network: Arsitecture, Algorithm, and Aplication. New Jersey : Prentice-Hall.

[4] Sachs Jonathan. "Digital Image Basics", http://www.dl-c.com/basics.pdf, Agustus 2009.

[5] Wardoyo Siswo, Wiryadinata Romi, Sagita Raya. "Sistem Presensi Berbasis Agoritma Eigenface Dengan Metode Principal Component Analysis”. Jurnal SETRUM Volume 3, No. 1, Juni 2014.

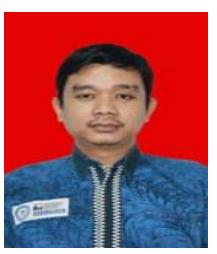

Hendra kurniawan finished graduate degree in Informatics and Business Institute Darmajaya in 2012. He works as a researcher in Informatics and Business Institute Darmajaya. His interests are information system and database.

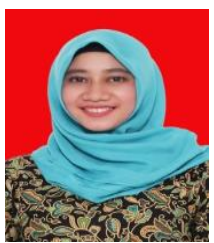

Melda Agarina finished graduate degree in IIB Darmajaya in 2014. Recently, she works as a researcher in Informatics and Business Institute Darmajaya. Her interests are database and software engineering.

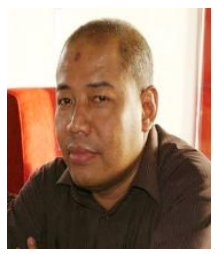

Suhendro Y. Irianto received his Master in Computers Science from The University of Indonesia, Jakarta Indonesia. He got Ph.D degree in Image Retrieval from the University of Bradford, United Kingdom in 2008. Currently, he works as the researcher in Informatics Engineering Department, Informatics and Business Institute Darmajaya, Indonesia. His interests are image retrieval, biometrics, pattern recognition, and multimedia database.

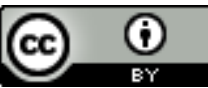

This work is licensed under a Creative Commons Attribution 4.0 International License.

DOI: $10.24297 /$ ijct.v16i7.6390 